Jurnal Psikologi Teori dan Terapan

2014, Vol. 5, No. 1, 1-6, ISSN: 2087-1708

\title{
Nilai Budaya Masyarakat Banjar Kalimantan Selatan: Studi Indigenous
}

\author{
Ermina Istiqomah $^{1}$ \\ Program Studi Psikologi Universitas Lambung Mangkurat Banjarbaru \\ Sudjatmiko Setyobudihono \\ Program Studi Keperawatan STIKES Cahaya Bangsa Banjarmasin
}

\begin{abstract}
This study was aimed to identify local values of Banjar society, South Kalimantan. Phenomenological method was used to reveal how participants' understanding of the local values. In-depth interviews were employed to collect data from three participants who were recruited by using purposive and snowball sampling. The three participants consist of a Banjar culture expert, a Banjar society informal leader, dan a researcher on Banjar issues. This study found that Banjar values can be categorized in four levels namely Banjar values in human and God, human and nature, interpersonal, and intrapersonal relations. In the context of human and God relation, the primary concept of Banjar value identified is berelaan which means sincerity and gratitude. Concerning human and nature relation, there is a Banjar prominent value bisa-bisa maandak awak that means adaptive to environment. At interpersonal level, the values identified are bubuhan (discussion to reach agreement), bedingsanakan (fraternity), betutulungan (mutual assistance), and bakalah bamanang (self-adjustment). The Banjar eminent values at intrapersonal level cover gawi manuntung (self-independent) and dalas balangsar dada (responsible).
\end{abstract}

Key words: Local values, Banjar society, indigeneous study

\begin{abstract}
Abstrak: Penelitian ini untuk mengidentifikasi nilai-nilai budaya lokal pada masyarakat Banjar Kalimantan Selatan. Metode kualitatif fenomenologis untuk mengembangkan pemahaman mengenai nilai-nilai budaya lokal. Teknik snowball digunakan dalam menggali data melalui wawancara dari satu informan ke informan lainnya. Subjek penelitian berjumlah 3 (tiga) orang, yaitu ahli budaya, akademisi dan tokoh masyarakat. Hasil menunjukkan nilai budaya Banjar; dalam hubungan manusia dengan Tuhan meliputi ikhlas dan syukur dengan konsep nilai berelaan. Manusia dengan alam, nilai konsepsi bisa-bisa maandak awak untuk menyesuaikan diri dengan lingkungan. Hubungan manusia dengan manusia meliputi nilai musyawarah, persaudaraan, gotong royong atau tolong menolong, penyesuaian diri, dengan konsep nilai bubuhan, bedingsanakan, betutulungan, dan bakalah bamanang. Manusia dengan diri sendiri, meliputi kerja keras, disiplin, koreksi diri, mengikuti perkembangan jaman, percaya pada diri sendiri, dan bertanggungjawab dengan konsep nilai gawi manuntung, dalas balangsar dada.
\end{abstract}

Kata Kunci: nilai-nilai lokal, masyarakat Banjar, kajian indigeneous

Korespondensi tentang artikel ini dapat dialamatkan kepada Ermina Istiqomah melalui e-mail: erminaistiqomah06@yahoo.com 
Indonesia dikenal dengan keragamannya. Penduduknya menunjukkan keragaman budaya, adat istiadat, suku, agama dan bahasa.Keragaman tersebut merupakan khazanah yang sangat bermakna dan memberikan bahan kajian yang luas, memberi manfaat untuk kehidupan masyarakat, pembangunan bangsa dan pengembangan dunia keilmuan (Zulkifli, 2008).

Salah satu provinsi di Indonesia yang memiliki kekhasan tersendiri adalah Kalimantan Selatan. Kalimantan Selatan adalah sebuah provinsi yang terletak di bagian tenggara pulau Kalimantan, memiliki kawasan dataran rendah di bagian barat dan pantai timur, serta dataran tinggi yang dibentuk oleh pegunungan meratus di tengah. Kondisi geografis Kalimantan Selatan lainnya banyak mempunyai rawa serta sungai, sedangkan suku terbesar di Kalimantan selatan adalah suku Banjar. Urang Banjar (orang Banjar) adalah kelompok etnis terbesar yang mendiami provinsi ini (Mohandas dkk, 2011).

Setiap masyarakat memiliki kebudayaan tertentu. Budaya tersebut merupakan bagian dari kehidupan masyarakat pendukungnya (Zulkifli, 2008)). Nilai budaya merupakan tingkat yang paling abstrak dari adat. Suatu sistem nilai budaya terdiri dari konsepsi-konsepsi, yang hidup dalam alam pikiran sebagaian besar warga masyarakat, mengenai hal-hal yang harus mereka anggap amat bernilai dalam hidup.Karena itu suatu sistem nilai budaya biasanya berfungsi sebagai pedo-man tertinggi bagi kelakuan manusia. Sistemsistem tata kelakuan manusia lain yang tingkatnya lebih konkrit, seperti aturanaturan khusus, hukum dan norma-norma, semuanya juga berpedoman kepada sistem nilai budaya itu (Koentjaraningrat, 2008)

Nilai lokal adalah nilai yang tumbuh dalam suatu konteks budaya tertentu, terbatas untuk suatu kelompok masyarakat tertentu.Nilai tidak berdiri sendiri dalam kondisi vakum, tetapi selalu terkait dengan konteks kehidupan sekelompok individu, yang selanjutnya dipengaruhi oleh lingkungan alam, iklim, sosial-ekonomi, dan lain-lain. Pemahaman akan perilaku manusia, yang terkait dengan pemahaman akan sistem nilai yang mempengaruhi perilaku akan sangat berpe-ngaruh dalam mengembangkan perilaku positif (Heriati, 2010).

Nilai lokal adalah salah satu elemen utama untuk mencapai kesuksesan (Gladwell, 2008).Hal ini menggambarkan pentingnya memahami nilai-nilai lokal yang ada didalam suatu masyarakat. Berdasarkan paparan diatas, timbul pertanyaan bagaimanakah nilai-nilai lokal pada masyarakan Banjar Kalimantan Selatan. Demikian, penting bagi kita untuk memahami dan mengetahui nilai-nilai lokal yang ada pada masyarakat Banjar Kalimantan Selatan.

Tujuan penelitian ini adalah mengidentifikasikonsepsi nilai-nilai lokal pada masyarakat Banjar Kalimantan Selatan. Studi area penelitian ini adalah Banjarmasin, ibu kota dari provinsi Kalimantan Selatan. Penelitian ini diharapkan dapat memberikan temuan informasi mengenai nilai-nilai budaya yang ada dan berkempang pada masyarakat Banjar Kalimantas Selatan.

Pentingnya mengetahui nilai-nilai lokal masyarakat Banjar sebagaimana diketahui para individu sejak kecil telah diresapi dengan nilai-nilai budaya yang hidup dalam masyarakatnya sehingga konsepsi-konsepsi itu sejak lama telah berakar dalam alam jiwa mereka. Itulah sebabnya nilai-nilai lokal tadi sukar digantikan dengan nilai-nilai budaya lain. Penelitian ini menunjukkan dan diketahui nilai-nilai lokal masyarakat Banjar yang spesifik atau khas yang tentunya berbeda dengan nilai lokal budaya lain. Kekhasan nilai lokal sebagai pembeda yang dianut masyarakat Banjar dapat dijadikan modal dalam memahami dan menyikapi masyarakat setempat yang menjadi keunggulan penelitian ini. 
Peneliti ingin mengkaji psikologi berkaitan dengan budaya Banjar atau yang disebut dengan Indigenous Psychology. Indigenous Psychology sendiri adalah kajian tentang perilaku manusia dan proses mental dalam konteks kultural yang mengatur nilai, konsep, system keyakinan, metodologi serta sumber-sumber yang pribumi sifatnya (Ho, 1998).

Indigenous psychology mempresentasikan sebuah pendekatan yang konteks (keluarga, sosial, kultural, dan ekologis) isinya (yakni makna, nilai, dan keyakinan) secara eksplisit dimasukkan kedalam desain penelitian. Peran para penelitilah yang mampu menerjemahkan pengetahuan episodek menjadi bentuk-bentuk analitik agar dapat diuji dan diverifikasi (Kim, 2010).Dari penelitian ini diharapkan akan mendapat pengetahuan psikologi berkaitan dengan realitas sosial dan budaya Banjar sendiri, bukan berdasarkan pengetahuan psikologi dari Barat.

Temuan ini bermanfaat sangat penting bagi dasar penelitian-penelitian selanjutnya untuk menggali lebih dalam pentingnya nilai-nilai lokal suatu masyarakat, khususnya masyarakat Banjar pada aplikasi kehidupan yang lebih luas. Bagi pemegang kebijakan, temuan penelitian ini dapat dijadikan kajian dan bahan pertimbangan dalam membina, mengembangkan dan melestarikan nilainilai lokal budaya Banjar sebagai modal pembangunan daerah khususnya dan nasional pada umumnya.

\section{Metode}

Penelitian ini menggunakan metode penelitian kualitatif fenomenologis untuk mengembangkan pemahaman mengenai nilai-nilai lokal. Moleong (2006) menyebutkan fenomenologis berusaha untuk masuk kedalam dunia konsepstual para subjek sedemikian rupa sehingga mengerti apa dan bagaimana suatu pengertian yang dikembangkan untuk mereka disekitar peristiwa dalam kehidupan sehari-hari.
Penelitian kualitatif fenomenologis disini menggunakan teknik snow-ball, yakni penggalian data melalui wawancara dari satu informan ke informan lainnya. Data dikumpulkan dengan wawancara kepada subjek penelitian yang berjumlah 3 (tiga) orang, yaitu akademisi peneliti (X), ahli budaya (Y), dan tokoh masyarakat (Z). Subjek penelitian adalah sumber utama data penelitian, yaitu yang memiliki mengenai variabel-variabel yang diteliti. Subjek penelitian, pada dasarnya, adalah yang akan dikenai kesimpulan hasil penelitian (Azwar, 2007).

Subjek penelitian menjadi informan yang memberikan informasi, meliputi informan kunci, yaitu subjek yang mengetahui dan memiliki informasi pokok yang diperlukan dalam penelitian. Pada penelitian ini sebagai key informan, peneliti memulai dari akademisi, yakni "X" seorang dosen peneliti budaya dan sastra PTN di Banjarmasin Kalimantan Selatan.

Peneliti memulai wancara dari orang yang dikenal dan memiliki relevansi untuk menjelaskan teoritis permasalahan yaitu akademisi. Kemudian berkelanjutan ke informan-informan untuk memperluas informasi wawancara yang telah diperoleh sebelumnya.Teknik analisis data yang digunakan adalah teknik deskriptif, yaitu mendeskripsikan atau menggambarkan data yang telah terkumpul sebagaimana adanya tanpa membuat kesimpulan yang berlaku secara umum.

\section{Hasil dan Pembahasan}

Hasil penelitian menunjukkan temuan sebagai berikut terdapat empat nilai budaya Banjar yaitu nilai budaya Banjar; dalam hubungan manusia dengan Tuhan, dalam hubungan manusia dengan manusia, dalam hubungan manusia dengan diri sendiri atau berkaitan dengan kegiatan manusia sebagai bentuk pengembangan diri, dan nilai budaya Banjar dalam 
hubungan manusia dengan alam. Hal ini seperti dikemukakan oleh X:

"Penelitian saya menunjukkan
bahwa di Kalimantan Selatan ini
budaya Banjar dapat digolongkan
menjadi 4 (empat), yaitu (1) nilai
budaya Banjar dalam hubungan
manusia dengan Tuhan, (2) nilai
budaya Banjar dalam hubungan
manusia dengan sesama manusia,
(3) nilai budaya Banjar dalam
hubungan manusia dengan diri
sendiri, dan (4) nilai budaya Banjar
dalam hubungan manusia dengan
alam" (S1/7).

Kemudian peneliti melanjutkan penggalian data kepada informan tambahan, yaitu budayawan (Y) dan tokoh masyarakat (Z). Dikatakan oleh Y bahwa:

"Budaya Banjar di dalam
lingkungan kerja misalnya di
Puskesmas, seperti nilai hubungan
manusia dengan Tuhan, kan kita
harus ikhlas dalam bekerja" (S2/4).

"Kedua, nilai budaya Banjar dalam hubungan dengan sesama, seperti kita lihat dimasyarakat adanya konsep bubuhan dan bedingsanakan. Jadi kita sama-sama harus saling membantu"(S2/6).

"Ketiga, hubungan dengan diri sendiri, ya harus bersungguhsungguh..menuntung dalam bekerja"(S2/8). "Untuk yang nomor empat, hubungan dengan alam, maksudnya dengan lingkungan ya kita harus bisa menyesuaikan diri, yaitu bisa-bisa maandak awak" (S2/11).

Tokoh masyarakat (Z) sebagai informan ketiga menguatkan pernyataan informan sebelumnya. $\mathrm{Z}$ mengatakan:

"Ya itu bu, kita harus ikhlas dan bersyukur dalam begawi (bekerja) karena kerja adalah ibadah kepada Allah SWT "(S3/4). Kita juga dalam bagawi harus batutulungan wan bedingsanakan, mau aja bakalah bamanang karena kita adalah saudara' (S3/8).

"Ibarat jar urang tu dalas balangsar dada, jadi juga harus bersungguh-sungguh dalam begawi" (S3/11). "Harus bisa menyesuaikan dengan lingkungan dimana kita berada, jadi kita urang Banjar bisa-bisa ma andak awak biar nyaman begawian.." (S3?13).

Hasil temuan dari ketiga informan tersebut diatas menunjukkan bahwa: Pertama, Wujud konsepsi berelaan merupakan nilai ikhlas dan syukur dan semata-mata untuk ibadah dan mendapat keridhoan Allah SWT.

Kedua, Pada sistem kekerabatan, baik karena keturunan maupun karena status sosial dan profesi, ada konsep bubuhan. Dalam konsepsi bubuhan termuat nilai bedingsanakan (persaudaraan), betutulungan (tolong menolong) dan mau haja bakalah bamanang (mau saja kalah menang) maksudnya mau saja memberi dan menerima.

Ketiga, nilai untuk pengembangan diri konsepsigawi manuntung, dalas balangsar dada yang maknanya seseorang harus mau berjuang dengan sungguhsungguh.

Keempat, nilai konsepsi bisa-bisa maandak awak untuk menyesuaikan diri dengan lingkungan.

Yang (2000) menyatakan indigenous psychology menganjurkan untuk menelaah pengetahuan, keterampilan, dan keyakinan yang dimiliki orang tentang dirinya dan bagaimana mereka menjalankan fungsinya dalam konteks keluarga, sosiol, kultural, dan ekologis mereka. Telaah ini menekankan pada upaya mendapatkan pemahaman deskriptif tentang fungsi manusia dalam konteks kultural.

Kim dan Barry (1993) mendefinisikan indigenous psychology sebagai kajian ilmiah tentang perilaku atau pikiran manusia yang native (asli), yang tidak 
ditransportasikan dari wilayah lain, dan yang dirancang untuk masyarakatnya. Indigenous psychology merepresentasikan paradigma ilmiah transaksional dimana individu-individu dianggap sebagai agen bagi tindakan mereka dan agen-agen kolektif melalui budayanya (Kim, 2000).

Orang adalah subjek dan sekaligus objek investigasi. Kita perlu mendapatkan sebuah pemahaman terintegrasi dari perspektif orang pertama, orang kedua, dan orang ketiga untuk mendapatkan gambaran lengkap tentang fungsi manusia. Dalam kehidupan sehari-hari orang memiliki pengetahuan fenomenologis, episodek, dan prosedural tentang tata cara mengelola lingkungannya, tetapi mereka mungki tidak memiliki keterampilan analitik untuk mendeskripsikan bagaimana hal itu dilakukan. Indigenous psychology menganjurkan untuk menelaah pengetahuan, keterampilan, dan keyakinan yang dimiliki orang tentang dirinya, dan mempelajari aspek-aspek ini dalam konteks alamiah (Kim, 2010).

Budaya adalah emergent property dari individu-individu yang berinteraksi dengan, mengelola dan mengubah lingkungan mereka. Melalui budaya kita berpikir, merasakan, berperilaku, dan mengelola realitas kita (Shweder, 1991).

Orang Banjar dengan kebudayaannya mempunyai unsur dominan, yaitu dari segi bahasa, yaitu bahasa banjar dan dari segi keberagamaannya adalah islam (Syarifuddin, dkk., 1967). Karena itu amat wajar jika budaya Banjar juga berkaitan dengan hubungan manusia dengan Tuhan. Ikhlas dan syukur dengan menekankan konsep berelaan dan semata-mata untuk ibadah dan mendapat keridhoan Allah SWT.

Nilai budaya Banjar dalam hubungan manusia dengan sesamanya juga berkaitan dengan sistem kekerabatan dan sikap keberagamaan (Islam) dari masyarakat Banjar. Pada sistem kekerabatan, baik karena keturunan maupun karena status soaial atau profesi, ada yang disebut bubuhan (Daud, 1997).

Dalam konsep bubuhan termuat nilai bedingsanakan (persaudaraan), betutulungan (tolong menolong) dan mau haja bakalah bamanang (mau saja kalah menang), maksudnya mau saja memberi dan menerima. Hal ini sesuai dengan salah satu keinginan pokok manusia, yaitu keinginan untuk menjadi satu dengan manusia lain di sekelilingnya atau masyarakat (Soekanto, 2004).

Bubuhan sebagai kesatuan sosial sangat kuat ikatannya dengan kegotongroyongan (Saleh, 1986). Orang hidup harus betutulongan (tolong menolong), jangan hidup saurang-saurang (Zulkifli, 2008).

Setiap masyarakat pasti mengalami perubahan, baik perubahan tersebut berlangsung lambat atau cepat, berpengaruh luas atau terbatas (Soekanto, 2004). Karena itu, orang Banjar juga terbuka terhadap pemikiran-pemikiran baru yang rasional, termasuk bagaimana melakukan kegiatan secara lebih praktis (Syarifuddin dan Amka, 2005). Hal ini sesuai dengan temuan nilai konsepsi dalas balangsar dada, artinya biarpun harus berselancar dada yang maknanya seseorang harus berjuang dengan sungguh-sungguh (Mugeni,dkk., 2004).

Orang banjar mengenal ungkapan gawi manuntung yang mengandung pengertian bahwa seseorang dalam mengerjakan sesuatu harus dapat menyelesaikannya dengan baik (Makkie dan Seman, 1994).

Nilai konsepsi bisa-bisa maandak awak untuk menyesuaikan diri dengan lingkungan. Bisa-bisa maandak awak atau menyeseuaikan diri. Nasehat ini biasanya diberikan agar dapat menyesuaikan diri dengan adat istiadat (Makkie dan Seman, 1996). 


\section{Simpulan}

Nilai budaya Banjar; dalam hubungan manusia dengan Tuhan meliputi ikhlas dan syukurdengan konsep nilai berelaan. Hubungan manusia dengan manusia meliputi nilai musyawarah, persaudaraan, gotong royong, tolong menolong, penyesuaian diri, dengan konsep nilai bubuhan, bedingsanakan, betutulungan, bakalah bamanang. Manusia dengan diri sendiri, meliputi kerja keras, disiplin, koreksi diri, mengikuti perkembangan jaman, percaya pada diri sendiri, dan bertanggungjawab dengan konsep nilai gawi manuntung, dalas balangsar dada. Manusia dengan alam, nilai konsepsi bisabisa maandak awak untuk menyesuaikan diri dengan lingkungan.

\section{Daftar Pustaka}

Azwar, S. (2007).Metodologi Penelitian. Yogyakarta. Pustaka Pelajar.

Daud, A. (1997). Islam dalam masyarakat Banjar(deskripsi dan analisisa kebudayaan Banjar). Jakarta: Raja Grafindo Persada.

Gladwell., M. (2008). Outliers : The Story of Success. New York : Little, Brown and Company.

Ho, D. F. (1998). Indigenous psychology: Asian perspectres. Journal of Cross-Cultural Psychology.

Kim, U. (2000).Indigenous, culture, and cross-cultural psychology : Theoretical, philosophical, and epistemological analysis. Asian Journal of Social Psychology, 3, 265-287.

Kim, U., \& Barry, J. W. (1993).Indigenous Psychologies: Experience and research in cultureal context. Newbury Park, CA:sage

Koentjaraningrat. (2008). Kebudayaan, Mentalitas dan Pembangunan. Jakarta. PT Gramedia Pustaka Utama.

Makkie \& Seman. (1996). Peribahasa dan Ungkapan Tradisional Bahasa
Banjar. Banjarmasin: Dewan Kesenian Daerah Kalimantan Selatan.

Moleung., L. J. (2006). Metode Penelitian Kualitatif. Bandung. PT Remaja Rosdakarya.

Migeni, Yayuk, dan Mahrita. (2004). Ungkapan Bahasa Banjar.Banjarbaru : Balai Bahasa Banjar.

Syarifuddin, \& Amka (1995).Pembidaan Budaya dalam Lingkungan Keluarga Daerah Kalimantan Selatan. Banjarmasin: Bagian Proyek Pengkajian dan Pembinaan Nilai-nilai Budaya Kalimantan selatan.

Yang, K.S. (2000). Monocultural and cross-cultural indigenous approaches : The royal road to development of balance global psychology. Asian Journal of Social Psychology, 3241-263.

Zulkifli (2008). Nilai Budaya Banjar dalam Cerita si Palui. Kandil. Edisi 7. Agustus - Oktober. Banjarmasin 